\title{
How do virtual world experiences bring about learning? A critical review of theories
}

\author{
Swee-Kin Loke \\ University of Otago
}

\begin{abstract}
While students do learn real-world knowledge and skills in virtual worlds, educators have yet to adequately theorise how students' virtual world experiences bring about this learning. This paper critically reviewed theories currently used to underpin empirical work in virtual worlds for education. In particular, it evaluated how applicable these theories' learning mechanisms are to virtual world-based learning. Eleven theories were identified from 80 journal papers. Four learning mechanisms were found to be applicable to virtual worlds: that students learn through reflection, verbal interactions, mental operations, and vicarious experiences. However, one commonly implied learning mechanism was found to be inapplicable to virtual worlds: that students undergo a physical sensorimotor experience of the real-world phenomenon through their virtual world actions. An alternative theory is needed to explain how students' virtual world actions might bring about learning, so as to help educators determine what exactly students can learn by performing virtual world actions.
\end{abstract}

\section{Introduction}

Educators have used many forms of virtual worlds for teaching. In this paper, virtual worlds refer to computer-based, multi-user virtual environments that simulate real or fictional life and that users experience using their graphical representations or avatars. Examples of such desktop virtual worlds include Second Life and Active Worlds. This definition excludes cave automatic virtual environment(CAVE) type virtual reality environments where users wear head-mounted displays and where their physical movements are tracked in real time because such sophisticated technologies are currently not readily available to educators.

Many educators have speculated on the potentials of virtual worlds, notably to mimic real-world settings and practices (e.g., Salmon, 2009; Warburton, 2009; Whitton, 2012). In this paper, real world means the physical world where students are expected to apply their knowledge and skills ultimately. For example, some educators believe that students can develop real-world clinical reasoning by practising clinical reasoning in virtual worlds (Boulos, Hetherington, \& Wheeler, 2007). Empirical studies in the area have since reported that students do learn such things as clinical decision-making (Loke, Blyth, \& Swan, 2012), ethics (Houser et al., 2011), and how to conduct home visits (Wilson, Brown, Wood, \& Farkas, 2013) by engaging in virtual world-based activities.

However, educators have not adequately theorised how students' virtual world experiences bring about the learning of real-world knowledge and skills. This is one instance of a general under-theorisation of research in virtual worlds for education: two literature reviews have concluded that the pedagogical basis for using virtual worlds is under-theorised (Savin-Baden et al., 2010) and the design of virtual worlds more intuitive than theory-based (Dalgarno \& Lee, 2010). Most empirical explorations in the area have a pragmatic rather than theoretical focus, typically focussing on practical issues when using virtual worlds for teaching (Wang \& Burton, 2013).

Theorising how virtual world experiences bring about learning can help educators determine what their students can learn from virtual world experiences. Learning theories explain the mechanisms or processes underlying particular learning experiences (Mayes \& de Freitas, 2004; Suppes, 1974). If educators knew which learning mechanisms apply to a particular learning experience, they would be better able to determine what their students can learn from that experience. For example, the theoretical mechanism underpinning Skinnerian teaching machines is operant conditioning, according to which students can acquire particular behaviours based on the types of reinforcement they get (Skinner, 1965). Knowing this, theoretically informed educators would use teaching machines to develop their students' ability to repeat transmitted information, but not the ability to act creatively in new situations (Piaget, 1970). 
To find out the theories currently used to explain how virtual world experiences might bring about the learning of real-world knowledge and skills, a systematic literature review of empirical work in virtual worlds for education was conducted. Two research questions guided the study:

(1) Which theories do educators use to underpin educational virtual worlds?

(2) How applicable are these theories' learning mechanisms to virtual worlds?

If educators knew which learning mechanisms apply to virtual worlds and which do not, they would be able to more precisely determine what their students can learn from virtual worlds and what they cannot.

This literature review aims to understand the theories used to underpin educational virtual worlds, unlike others that sought to map current educational uses of virtual worlds (e.g., de Freitas, 2008; Hew \& Cheung, 2010; Kim, Lee, \& Thomas, 2012). For example, de Freitas (2008) mapped virtual worlds to be used for role plays, socialisation, and training.

Four other literature reviews are similar in that they also sought to identify learning theories used to design educational virtual worlds. All four reported the predominance of experiential learning, social constructivist, and constructivist theories (Dass, Dabbagh, \& Clark, 2011; Mikropoulos \& Natsis, 2011; Savin-Baden et al., 2010; Wang \& Burton, 2013). However, they are different from this review in the following ways: firstly, Savin-Baden et al.’s (2010) review was not a systematic literature review, and hence did not summarise the theories comprehensively. Secondly, two of the reviews are different in scope: Wang and Burton (2013) limited their search to publications on Second Life and excluded other virtual worlds such as Active Worlds, River City, and Quest Atlantis (included in this review); Mikropoulos and Natsis' (2011) review was broader and included other virtual reality applications such as head-mounted displays and haptic systems. Thirdly, none of the four reviews focussed on how applicable the theories are to virtual world-based learning. Instead, Dass et al. (2011) and Mikropoulos and Natsis (2011) focussed inversely on how adequately virtual worlds support the kinds of learning described in learning theories (e.g., how well virtual world group discussions support social constructivist learning).

\section{Method}

On 16 May 2013, three databases were searched using "virtual world*” and “education (subject)" as keywords. Results were limited to peer-reviewed papers published during 2008-2012 in English.

The search yielded 206 papers from ERIC Proquest, 240 from Academic Search Complete, and 49 from PsycINFO (a total of 437 distinct publications, taking overlaps into account). The choice of the three databases was reasonable and sufficient because they jointly indexed an estimated 12,000 journals as of January 2013. They also included the ten key educational technology journals listed by Atkinson (2012). Moreover, other scholars in the field frequently used these databases (e.g., Hew \& Cheung, 2010; Wang \& Burton, 2013).

All 437 abstracts were read and 80 relevant papers (published in 52 different journals) were identified. Relevant papers consisted of empirical work involving virtual worlds as defined above, implementation with students and in mainstream curriculum (e.g., not library services). Discarded papers included literature reviews, conceptual papers (e.g., speculating about the educational potential of virtual worlds), empirical work not involving virtual worlds as defined above (e.g., laparoscopic simulators), and empirical work involving learning objectives bound within the virtual world (e.g., computer science students programming a virtual world).

The unit of analysis was the individual paper. As each relevant paper was read, the following information was recorded in a summary table: first author, paper's title, year of publication, journal's name, and theory or theories used. The theories were often explicitly stated, for example:

- “our research [was] guided by an experiential learning pedagogy” (Mathews, Andrews, \& Luck, 2012, p. 21)

- "Pedagogical considerations arise from the constructivist, experiential, and problembased learning models” (Cook, 2012, p. 523). 
Where there was ambiguity about the theories used (e.g., when authors stated that students were "learning by doing" with no further precision), it was coded that no explicit theory was used.

Eight of the theories found were variations of more foundational theories. These eight theories were each used in only one paper. To further summarise the data, these eight theories were coded as the learning theory they are derived from:

- computer-supported collaborative learning as social constructivism (based on Stahl, Koschmann, \& Suthers, 2006)

- $\quad$ Salmon's five-stage model of e-tivities as social constructivism (based on Salmon, 2007)

- Deutschmann and Panichi's (2009a) task design framework as social constructivism (based on Deutschmann \& Panichi 2009b)

- distributed cognition, activity theory, and ecological psychology as situated learning (based on Greeno, 2006)

- Barab, Gresalfi, and Ingram-Goble's (2010) theory of transformational play as experiential learning and projective identity model (based on Barab et al., 2010)

- $\quad$ Pedler’s (2007) action learning process as experiential learning (based on Pedler, 2007).

\section{Findings and discussion}

\section{Theories used}

Eleven theories were used in the 80 relevant papers. Of the relevant papers, 24 were not explicitly underpinned by any theory. Of the 56 remaining papers, 70 explicit statements of the theories used were located. Some papers were underpinned by more than one theory. From the 70 explicit statements, 11 different theories that underpin virtual worlds for education were identified (see Figure 1 for the distribution of theories and go to http://bit.ly/1b8qsK5 for the full list of papers and corresponding theories).

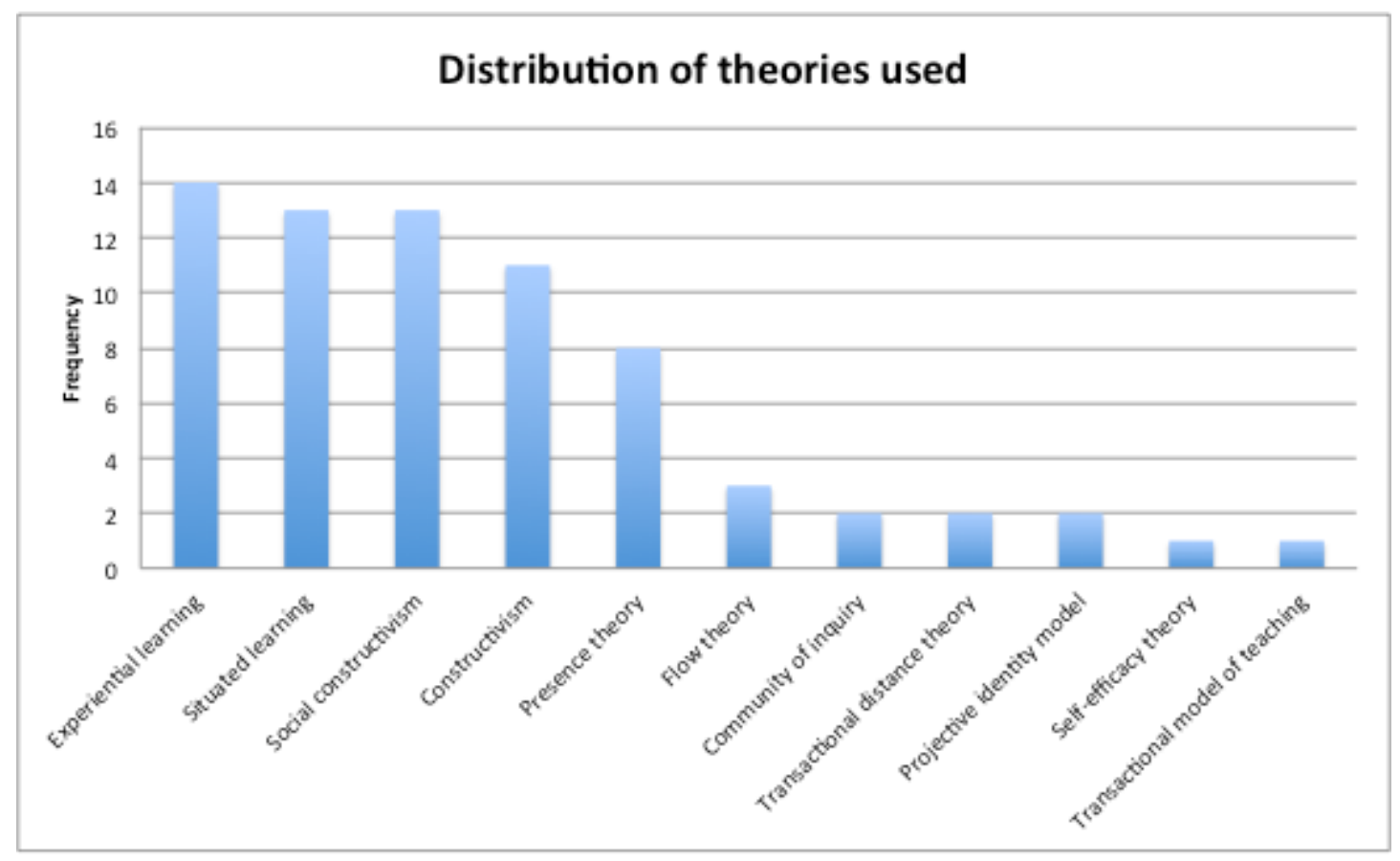

Figure 1. Distribution of theories underpinning empirical work in virtual worlds for education

These findings concur with four previous literature reviews that also reported the predominance of experiential learning, social constructivist, and constructivist theories in virtual world-related work (Dass et al., 2011; Mikropoulos \& Natsis, 2011; Savin-Baden et al., 2010; Wang \& Burton, 2013). This review 
reveals a fuller range of theories and their distribution, and the frequent use of presence theory, absent from the four previous literature reviews.

There was no explicit theory used in 24 papers (30\%), supporting observations that many educators only use implicit theory when designing teaching innovations in virtual worlds (Savin-Baden et al., 2010). In the related field of game-based learning (including virtual game worlds), a meta-analysis showed that an overwhelming $86 \%$ of studies published between 1971 and 2009 were not explicitly underpinned by any learning theory (Wu, Hsiao, Wu, Lin, \& Huang, 2012).

\section{Critical evaluation}

Seven of the 11 theories will now be evaluated regarding how applicable their learning mechanisms are to virtual worlds. Four theories are excluded because they neither apply to, nor illuminate, the virtual world learning experience. Two of these four theories do not explain learning processes: Csikszentmihalyi's (1990) flow theory explains how people achieve well-being and happiness; Dees et al.'s (2007) transactional model of teaching is a framework meant to guide teacher reflection. The other two excluded theories aim mainly to compensate for the separation of teachers and students in distance education and focus mainly on text-based communication (not on virtual worlds involving avatars and situated actions). Garrison, Anderson, and Archer's (1999) community of inquiry framework prescribes, for example, that educators create a safe online environment where students can communicate openly; Moore's (1993) transactional distance theory prescribes that educators use technologies featuring interpersonal communication so as to reduce the transactional distance between teachers and students.

The critical evaluation of the seven theories is divided into two parts: first, five learning theories will be examined. It was found that, when applied to virtual worlds, these theories commonly imply that students gain a physical sensorimotor experience of the real-world phenomenon through their virtual world actions. In the second part, two other theories will be examined in terms of their ability to explain how students' virtual world actions might be similar to a physical sensorimotor experience of the real-world phenomenon.

\section{Experiential learning}

The majority of authors using experiential learning theory to underpin their work cited Dewey (1938) and Kolb (1984). Kolb drew extensively from Dewey's work, and hence Kolb's experiential learning theory will be the focus here. The theory critiques the transmission model of teaching where teachers deliver a static set of information to students. It proposes instead that students learn through their personal lived experiences.

The theory's mechanism consists of active experimentation in the world yielding "concrete experience" (Kolb, 1984, p. 30), followed by reflection to make meaning of the concrete experience. The theory holds that, by reflecting on their real-life experiences, students will be able to act creatively in new situations in the real world.

When experiential learning theory is applied to virtual worlds, it is implied that students undergo concrete experiences of the real-world phenomenon in virtual worlds. For example, some authors claim that virtual worlds offer students "real-world, hands-on experiences" (Leggette, 2012, p. 125) and "concrete experiences" (Wehner, Gump, \& Downey, 2011, p. 280). However, it is implausible that students undergo a concrete experience of the real-world phenomenon in virtual worlds. Unless the correspondence between the virtual world experience and the concrete experience is explained, experiential learning theory is inadequate in explaining how the virtual world experience might bring about learning of real-world knowledge and skills.

Experiential learning theory also highlights the importance of reflection to make meaning of concrete experiences. For example, after role-playing as doctors in a virtual hospital, medical students hold a debriefing session with their tutor to examine their virtual performance (Loke et al., 2012). While debriefing is not strictly part of the virtual world experience, it is integral to experiential learning theory. It is plausible that students can make meaning of their virtual world performance by reflecting on it: the reflection phase is similar whether students' performance is undertaken in the virtual or real world. In this case, experiential learning theory does explain how the virtual world experience brings about learning. 


\section{Situated learning}

The majority of authors using situated learning theory to underpin their work cited Lave and Wenger's work (Lave \& Wenger, 1991; Wenger, 1998). The theory critiques the idea that human cognition resides in the individual's head, independent of context. The theory proposes instead that the ways in which human beings think and act are inherently coupled with their sociocultural context (Lave, 1988).

When situated learning theory is applied to virtual worlds, it is implied that the virtual world would provide a realistic enough context to lead students to think and act as they would in real-world situations. For example, in a virtual mine, mining personnel are tasked to apply the correct procedures to an emergency evacuation scenario (Garrett, 2012). It is implied that the virtual mine would provide a realistic enough context to lead mining personnel to think and act as they would in a real mine.

It is plausible that students role-playing in virtual worlds think as they would in real-world situations: Garrett (2012) concluded that mining personnel needed to apply their real-world thinking processes to resolve emergency evacuation tasks (e.g., decide on movement speed so that "physical" exertion did not deplete oxygen supply prematurely). In this case, situated learning theory does explain how the virtual world experience brings about learning of real-world knowledge and skills.

However, it is implausible that students role-playing in virtual worlds act as they would in real-world situations: deciding on one's movement speed in a virtual mine (by pressing a button) is not the same action as adjusting one's physical exertion in a real mine. It is implausible that learners undergo such a physical experience in virtual worlds. In this case, unless the correspondence between the virtual world experience and the physical experience is explained, situated learning theory is inadequate in explaining how the virtual world experience might bring about the learning of real-world knowledge and skills.

\section{Social constructivism}

The majority of authors using social constructivism to underpin their work cited Vygotsky (1978). The Vygotskyan theory of social constructivism critiques the idea that learning results either solely from environmental stimulation or solely from biological maturation. The theory holds instead that learning results from a person's internalisation of social practices.

The theory's mechanism is internalisation, or the transformation of knowledge from the social to individual planes. Internalisation arises from social interactions. For example, during their final year of medical education, trainee doctors are often paired with experienced clinicians in the hope that, by practising clinical reasoning with their mentors, the trainees would develop their individual clinical reasoning ability.

When social constructivism is applied to virtual worlds, it is implied that these social interactions occur in students' virtual world experience. For Vygotsky (1978), these social interactions involve both verbal and bodily hands-on activity: "children solve practical tasks with the help of their speech, as well as their eyes and hands" (p. 26). The following is an example of a hands-on action in a virtual world: in a virtual construction plant, three trainees dismantle a tower crane collaboratively (Guo, Li, Chan, \& Skitmore, 2012). Using Nintendo Wii controllers, one trainee operates another tower crane while the other two connect the crane elements to the hook. Taking social interaction as a predominantly hands-on activity, it is implied that the virtual world experience brings about learning in the same way as a hands-on experience. However, it is implausible that students undergo a hands-on experience of the real-world phenomenon in virtual worlds: controlling a virtual tower crane on a computer screen is not the same hands-on experience as controlling a real tower crane. In this case, unless the correspondence between the virtual world experience and the hands-on experience is explained, social constructivism is inadequate in explaining how the virtual world experience might bring about learning.

Social interactions can alternatively be taken to be a predominantly verbal interaction. For example, in the virtual construction plant described above, the three trainees verbally communicate with one another to dismantle the tower crane successfully. Taking this perspective, it is implied that the virtual world experience brings about learning in the same way as a verbal interaction with others. This implication is plausible because a verbal interaction is similar whether in the virtual or real world. In this case, social constructivism does explain how the virtual world experience brings about the learning of real-world knowledge and skills. 


\section{Constructivism}

The majority of authors using constructivism to underpin their work cited Dede (1995), Dickey (2005), and Papert (1980), whose work can be traced back to the Piagetian theory of constructivism. The theory critiques the transmission model of teaching that solely emphasises the impact of the environment on cognitive development. Instead, the theory foregrounds the role of learners in constructing their own knowledge, holding that "a truth is never truly assimilated as a truth except insofar as it has been first been reconstructed or rediscovered by means of some activity adequate to that task” (Piaget, 1970, p. 26).

This activity constitutes the theory's mechanism. It involves interactions between learners and their environment, during which learners continually re-interpret their experience to match their conceptualisations (assimilation) and adjust their conceptualisations to match their experience (accommodation).

When constructivism is applied to virtual worlds, it is implied that these learner-environment interactions occur in students' virtual world experience. Piaget (1970) was clear that such interactions involve both bodily sensorimotor activity and mental operations. The following is an example of a "bodily" interaction in a virtual world: in a virtual hospital where medical students role-play as doctors, students click on the virtual patient's chest to perform a "physical" examination and receive feedback in the form of heart sounds (Loke et al., 2012). Taking reconstruction as a predominantly sensorimotor activity, it is implied that the virtual world experience brings about learning in the same way as a sensorimotor experience. However, it is implausible that students undergo a sensorimotor experience of the real-world phenomenon in virtual worlds: clicking on the virtual patient's chest is not the same sensorimotor experience as physically examining a human patient. In this case, unless the correspondence between the virtual experience and the sensorimotor experience is explained, constructivism is inadequate in explaining how the virtual world experience might bring about learning.

Learner-environment interactions can alternatively be taken to be a predominantly mental operation. For example, in the virtual hospital described above, medical students mentally eliminate improbable diseases based on their virtual patient's responses and decide if a "physical" examination is needed. Taking learner-environment interactions as a mental operation, it is implied that the virtual world experience brings about learning in the same way as a mental operation. This implication is plausible because a student's mental operation (e.g., decision-making) is similar whether in the virtual or real world. For example, Roy, Wilkinson, Walker, and Blyth (2013) examined the construct validity of role-playing in a virtual hospital and reported that the clinical decision-making required in a virtual clinical case resembles real-world clinical decision-making. In this case, constructivism does explain how the virtual world experience brings about learning.

\section{Self-efficacy theory}

The authors who used self-efficacy theory to underpin virtual worlds for learning cited Bandura's (1997) work. In this theory, self-efficacy is defined as people's personal beliefs about their capability to complete a particular task. Self-efficacy is influenced by four factors:

(1) actual performances or what people do firsthand (enactive experiences)

(2) watching peers successfully perform the task (vicarious experiences)

(3) verbal persuasion that lead people into believing that they can overcome challenges; and

(4) physiological and affective states.

For example, enactive experiences influence self-efficacy in the following way: past successes in performing a particular task will raise one's self-efficacy in performing the task in future; past failures will lower it.

When self-efficacy theory is applied to virtual worlds, it is implied that enactive experiences and/or vicarious experiences occur in students' virtual world experience. The following is an example of enactive experiences in a virtual world: in a virtual Chinese restaurant, language students are tasked to order food in Mandarin (Henderson, Huang, Grant, \& Henderson, 2012). This virtual experience is expected to raise their self-efficacy in ordering food in the real world, as would a first-hand experience in a real Chinese restaurant. However, while it is plausible that ordering food in a real restaurant could serve as an enactive experience to ordering food in the real world, it is less plausible that ordering food in a virtual restaurant could serve as an enactive experience to ordering food in the real world. In this case, 
unless the correspondence between the virtual world experience and the real-world experience is explained, self-efficacy theory is inadequate in explaining how the virtual world experience might bring about the learning of real-world knowledge and skills.

The virtual world experience can alternatively be taken to be the student's vicarious experience. For example, in the virtual restaurant described above, getting students to observe their classmates' avatars order food in a virtual restaurant is expected to raise their self-efficacy in ordering food in the real world, as would observing their classmates order food in a real restaurant. If taking this perspective, it is implied that the virtual world experience influences self-efficacy in the same way as a vicarious experience. This implication is plausible because a student's vicarious experience is similar whether in the virtual or real world. Neuroscience research also suggests that it is plausible that a student's mirror neurons would fire while observing another avatar perform an action (de Freitas, 2008). In this case, self-efficacy theory does explain how the virtual world experience brings about learning.

The five learning theories above adequately explain how four learning mechanisms are applicable to virtual worlds: that students learn through reflection, verbal interactions, mental operations (e.g., decision-making), and vicarious experiences.

However, when applied to virtual worlds, the five learning theories commonly imply that students undergo a physical sensorimotor experience of the real-world phenomenon through their virtual world actions. This implication is implausible unless the correspondence between the virtual world action and real-world action is explained. The two remaining theories, presence theory and the projective identity model, have been used to explain this correspondence.

\section{Projective identity model}

The authors who used the projective identity model to underpin virtual worlds for learning cited Gee's (2003) work in video games for learning. The model explains how gamers learn to become certain kinds of people (e.g., scientists, footballers) through the interaction between their real-world and virtual identities. Using the video game Lara Croft: Tomb Raider as an example: to play Lara Croft successfully, gamers would have to adopt their virtual character's goals and values (e.g., to stop enemies from obtaining a powerful ancient relic) as well as project their own goals and values into Lara Croft (e.g., to minimise the number of mutants Lara kills). It is through the interaction between gamers' real and virtual identities that their "projective identity" (Gee, 2003, p. 55) is formed and that their avatar becomes their "surrogate mind and body" (Gee, 2008, p. 258).

According to Gee (2008), the mechanism underlying the projective identity model is Clark's (1997) extended mind theory. This theory holds that human cognition is not limited to our heads, but extends into the local environment, "parasitizing environment resources” (p. 63). For example, while using a calculator, a person might offload some cognitive load (e.g., the recall of previously stored numbers) onto the machine. Clark (1997) claims that the user's brain and the calculator might become so tightly coordinated that the inner and outer systems work together "as a single integrated computational unit" (p. 66).

When the extended mind theory is applied to virtual worlds, it is implied that the student and her avatar could form such an integrated computational unit. However, forming such a computational unit does not imply that the student's avatar would necessarily become her surrogate mind and body. The student might simply be making use of her avatar as she would a calculator. Therefore, the extended mind theory does not explain how a student's virtual world action might correspond to her real-world physical action.

\section{Presence theory}

The majority of authors using presence theory to underpin their work cited Blascovich (2002), Heeter (1992), Slater (1999), Steuer (1993), Winn (1993), and Witmer and Singer (1998). Many definitions of "presence" exist in the field of virtual reality. Witmer and Singer's (1998) is one of the most commonly accepted: "Presence is defined as the subjective experience of being in one place or environment, even when one is physically situated in another” (p. 225). Presence theory assumes that, if a user experiences a high degree of presence in virtual reality, the psychological processes activated by her interactions with virtual reality will be similar to those activated by her interactions with the physical world (Winn, 1993). For example, to treat fear of flying, patients are exposed to a virtual airplane in the hope of activating the 
same emotional anxiety as when exposed to an actual airplane (Rothbaum, Hodges, Smith, Lee, \& Price, 2000). In virtual worlds for education, if a student experiences a high degree of presence, it is implied that she would experience a similar psychological state as when she is performing a real-world action.

Care must be taken in applying presence theory to desktop virtual worlds: researchers in the field of virtual reality have rarely studied presence in desktop virtual worlds (Schroeder, 2010). Instead, these researchers mostly investigate CAVE-type virtual reality environments where users' physical movements are tracked.

Researchers in virtual reality are divided on whether users can experience presence in desktop virtual worlds. This depends on their conceptions of how presence is generated: one group believes that presence is more dependent on the virtual reality system's technological features. For example, Steuer (1993) recommends vivid graphics to generate presence in virtual reality. This group would classify desktop virtual worlds as non-immersive because of their relatively low graphical and behavioural realism (Bailenson \& Blascovich, 2004; Schroeder, 2010; Winn, 1993). For this group, immersive environments include CAVE-type systems where users control avatars in naturalistic ways (e.g., user's arm movements control avatar's arms). If taking this perspective, presence theory states that desktop virtual worlds are ineffective in generating presence in virtual reality, and that a student's virtual world action does not correspond to her real-world physical action.

The other group of researchers believes that presence is more dependent on people's psychological responses and less on technological features (Slater, 1999). This group believes that people can mentally evoke a sense of presence in desktop virtual worlds (as well as in other low-tech contexts such as reading novels and watching movies). For example, Regenbrecht and Schubert (2002) conducted an experiment involving a desktop video game and reported that both actual interactions and the gamers' perceived interaction possibilities increased their sense of presence in the game.

However, Regenbrecht (personal communication, June 11, 2014) asserted that many actions in Second Life are so unrealistic and cartoonish that they are likely to hinder people's psychological efforts in evoking presence, causing many breaks in presence (Slater \& Steed, 2000). For example, in a virtual hospital, some students did express that Second Life's built-in animation of avatars typing in mid-air (to signal text chatting) made the patient-doctor interaction less believable (Loke et al., 2012). Compared to commercial video games, actions in Second Life are typically depicted in rudimentary ways (e.g., the avatar's arm tends to flail unrealistically by default when interacting with objects). It is impossible to verify if all other desktop virtual worlds also feature cartoonish actions; Second Life is the most popular virtual world in education (Wang \& Burton, 2013). Therefore, even if presence is dependent on people's psychological responses, I contend that students can at best evoke a sense of presence intermittently in desktop virtual worlds. Regarding virtual world actions, given that virtual world actions are likely to be cartoonish and cause breaks in presence, I speculate that students are unlikely to feel a sense of presence when undertaking virtual world actions in desktop virtual worlds. In turn, presence theory would indicate that a student's virtual world action is unlikely to correspond to her real-world physical action.

\section{Conclusions}

To find out the theories currently used to explain how the virtual world experience might bring about the learning of real-world knowledge and skills, a systematic literature review of empirical work in virtual worlds for education was conducted. Eleven theories were identified and seven reviewed. The seven theories adequately explain how four learning mechanisms are applicable to virtual worlds: that students learn through reflection, verbal interactions, mental operations (e.g., decision-making), and vicarious experiences. Knowing this, educators can more precisely determine what students can learn in virtual worlds: for example, in a virtual hospital, medical students can learn to decide when is an appropriate time to intubate a patient, but cannot learn how to physically insert the tube into a patient.

However, one commonly implied learning mechanism is inapplicable to virtual worlds: that students undergo a physical sensorimotor experience of the real-world phenomenon through their virtual world actions. As such, educators should be cautious in suggesting that virtual world experiences could replace real-world internships, as suggested by Drake-Bridges, Strelzoff, and Sulbaran (2011) and Vergara, Caudell, Goldsmith, and Alverson (2008). The physical experience is still very much needed. Also, it is 
questionable whether "learning-by-doing” (Dede, 1995, p. 46) is the best way to conceive learning in desktop virtual worlds, unless "doing” refers only to verbal interactions and decision-making, and not to embodied actions. Further inquiry will be carried out to determine a better way to conceive learning in virtual worlds.

An alternative theory is needed to explain how students' virtual world actions might bring about the learning of real-world knowledge and skills. Explaining this is important because offering students the experience to undertake "embodied actions" (Dalgarno \& Lee, 2010, p. 16) and "performative learning” (Warburton, 2009, p. 421) has been claimed to be a key affordance of virtual worlds. Such an alternative theory would help educators determine what exactly students can and cannot learn by performing virtual world actions.

\section{Acknowledgements}

I would like to thank Dr Clinton Golding and Dr Sarah Stein for their comments on earlier drafts of this paper, and Dr Holger Regenbrecht for helping me understand research on telepresence in the field of virtual reality.

\section{References}

Atkinson, R. (2012). AJET's rankings. Australasian Journal of Educational Technology, 28(8), iii-v.

Bailenson, J., \& Blascovich, J. (2004). Avatars. In W. S. Bainbridge (Ed.), Encyclopedia of humancomputer interaction (pp. 64-68). Great Barrington, MA: Berkshire Publishing Group.

Bandura, A. (1997). Self-efficacy. New York, NY: Freeman.

Barab, S. A., Gresalfi, M., \& Ingram-Goble, A. (2010). Transformational play. Educational Researcher, 39(7), 525-536. doi:10.3102/0013189X10386593

Blascovich, J. (2002). Social influence within immersive virtual environments. In R. Schroeder (Ed.), The social life of avatars (pp. 127-145). London: Springer. doi:10.1007/978-1-4471-0277-9_8

Boulos, M. N. K., Hetherington, L., \& Wheeler, S. (2007). Second Life: An overview of the potential of 3-D virtual worlds in medical and health education. Health Information and Libraries Journal, 24(4), 233-245. doi:10.1111/j.1471-1842.2007.00733.x

Clark, A. (1997). Being there. Cambridge, MA: MIT Press.

Cook, M. J. (2012). Design and initial evaluation of a virtual pediatric primary care clinic in Second Life ${ }^{\circledR}$. Journal of the American Academy of Nurse Practitioners, 24(9), 521-527. doi:10.1111/j.17457599.2012.00729.x

Csikszentmihalyi, M. (1990). Flow. New York, NY: HarperPerennial.

Dalgarno, B., \& Lee, M. J. W. (2010). What are the learning affordances of 3-D virtual environments? British Journal of Educational Technology, 41(1), 10-32. doi:10.1111/j.1467-8535.2009.01038.x

Dass, S., Dabbagh, N., \& Clark, K. (2011). Using virtual worlds. Quarterly Review of Distance Education, 12(2), 95-111.

De Freitas, S. (2008). Serious virtual worlds: A scoping study. Joint Information Systems Committee. Retrieved from http://www.jisc.ac.uk/media/documents/publications/seriousvirtualworldsv1.pdf

Dede, C. (1995). The evolution of constructivist learning environments. Educational Technology, 35(5), 46-52.

Dees, D. M., Ingram, A., Kovalik, C., Allen-Huffman, M., McClelland, A., \& Justice, L. (2007). A transactional model of college teaching. International Journal of Teaching and Learning in Higher Education, 19(2), 130-139.

Deutschmann, M., \& Panichi, L. (2009a). Instructional design, teacher practice and learner autonomy. In J. Molka-Danielsen \& M. Deutschmann (Eds.), Learning and teaching in the virtual world of Second Life (pp. 27-44). Trondheim: Tapir Academic Press.

Deutschmann, M., \& Panichi, L. (2009b). Talking into empty space? Signalling involvement in a virtual language classroom in Second Life. Language Awareness, 18(3-4), 310-328. doi:10.1080/09658410903197306

Dewey, J. (1938). Experience and education. New York, NY: Macmillan.

Dickey, M. D. (2005). Three-dimensional virtual worlds and distance learning. British Journal of Educational Technology, 36(3), 439-451. doi:10.1111/j.1467-8535.2005.00477.x

Drake-Bridges, E., Strelzoff, A., \& Sulbaran, T. (2011). Teaching Marketing through a micro-economy in virtual reality. Journal of Marketing Education, 33(3), 295-311. doi:10.1177/0273475311420236 
Garrett, M. (2012). Developing knowledge for real world problem scenarios: Using 3D gaming technology within a problem-based learning framework (Unpublished doctoral dissertation). Edith Cowan University, Perth, Australia.

Garrison, D. R., Anderson, T., \& Archer, W. (1999). Critical inquiry in a text-based environment. The Internet and Higher Education, 2(2-3), 87-105. doi:10.1016/S1096-7516(00)00016-6

Gee, J. P. (2003). What video games have to teach us about learning and literacy. New York, NY: Palgrave Macmillan.

Gee, J. P. (2008). Video games and embodiment. Games and Culture, 3(3-4), 253-263. doi:10.1177/1555412008317309

Greeno, J. G. (2006). Learning in activity. In K. Sawyer (Ed.), The Cambridge handbook of the Learning Sciences (pp. 79-96). New York, NY: Cambridge University Press.

Guo, H., Li, H., Chan, G., \& Skitmore, M. (2012). Using game technologies to improve the safety of construction plan operations. Accident Analysis and Prevention, 48, 204-213. doi:10.1016/j.aap.2011.06.002

Heeter, C. (1992). Being there. Presence: Teleoperators and Virtual Environments, 1(2), 262-271.

Henderson, M., Huang, H., Grant, S., \& Henderson, L. (2012). The impact of Chinese language lessons in a virtual world on university students' self-efficacy beliefs. Australasian Journal of Educational Technology, 28(3), 400-419. Retrieved from http://ascilite.org.au/ajet/submission/index.php/AJET/index

Hew, K. F., \& Cheung, W. S. (2010). Use of three-dimensional (3-D) immersive virtual worlds in K-12 and higher education settings: A review of the research. British Journal of Educational Technology, 41(1), 33-55. doi:10.1111/j.1467-8535.2008.00900.x

Houser, R., Thoma, S., Coppock, A., Mazer, M., Midkiff, L., Younanian, M., \& Young, S. (2011). Learning Ethics through virtual fieldtrips. International Journal of Teaching and Learning in Higher Education, 23(2), 260-268.

Kim, S. H., Lee, J., \& Thomas, M. K. (2012). Between purpose and method: A review of educational research on 3D virtual worlds. Journal of Virtual Worlds Research, 5(1), 1-18.

Kolb, D. A. (1984). Experiential learning. Englewood Cliffs, NJ: Prentice-Hall.

Lave, J. (1988). Cognition in practice. New York, NY: Cambridge University Press. doi:10.1017/CBO9780511609268

Lave J., \& Wenger, E. (1991). Situated learning. Cambridge, MA: Cambridge University Press. doi:10.1017/CBO9780511815355

Leggette, H. (2012). Experiential learning using Second Life ${ }^{\circledR}$. Journal of Agricultural Education, 53(3), 124-136. doi:10.5032/jae.2012.03124

Loke, S. K., Blyth, P. \& Swan, J. (2012). Student views on how role-playing in a virtual hospital is distinctively relevant to medical education. In M. Brown, M. Hartnett, \& T. Stewart (Eds.), Future challenges, sustainable futures (pp. 565-574). Retrieved from

http://www.ascilite.org.au/conferences/wellington12/2012/images/custom/loke\%2c_swee-kin__student.pdf

Mathews, S., Andrews, L., \& Luck, E. (2012). Developing a Second Life virtual field trip for university students. Educational Research, 54(1), 17-38. doi:10.1080/00131881.2012.658197

Mayes, T., \& de Freitas, S. (2004). Review of e-learning theories, frameworks and models. London: Joint Information Systems Committee.

Mikropoulos, T. A., \& Natsis, A. (2011). Educational virtual environments: A ten-year review of empirical research (1999-2009). Computers \& Education, 56(3), 769-780. doi:10.1016/j.compedu.2010.10.020

Moore, M. G. (1993). Theory of transactional distance. In D. Keegan (Ed.), Theoretical principles of distance education (pp. 22-38). New York, NY: Routledge.

Papert, S. (1980). Mindstorms. Brighton: Harvester Press.

Pedler, M. (2007). A manager's guide to self-development. Maidenhead: McGraw-Hill.

Piaget, J. (1970). Science of education and the psychology of the child. New York, NY: Orion Press.

Regenbrecht, H., \& Schubert, T. (2002). Real and illusory interactions enhance presence in virtual environments. Presence, 11(4), 425-434. doi.:10.1162/105474602760204318

Rothbaum, B. O., Hodges, L., Smith, S., Lee, J. H., \& Price, L. (2000). A controlled study of virtual reality exposure therapy for the fear of flying. Journal of Consulting and Clinical Psychology, 68(6), 1020-1026. doi: 10.1037/0022-006X.68.6.1020

Roy, M., Wilkinson, T., Walker, R., \& Blyth, P. (2013). Virtual reality based clinical cases: a novel method for assessment of competence and clinical reasoning ability. Paper presented at the Australian 
\& New Zealand Association for Health Professional Educators, Melbourne. Retrieved from http://media.wix.com/ugd/363deb_f370150b93e4b9df09f7fd44d588dc7c.pdf

Salmon, G. (2007). The tipping point. ALT-J, 15(2), 171-172. doi:10.1080/09687760701482275

Salmon, G. (2009). The future for (second) life and learning. British Journal of Educational Technology, 40(3), 526-538. doi:10.1111/j.1467-8535.2009.00967.x

Savin-Baden, M., Gourlay, L., Tombs, C., Steils, N., Tombs, G., \& Mawer, M. (2010). Situating pedagogies, positions and practices in immersive virtual worlds. Educational Research, 52(2), 123133. doi:10.1080/00131881.2010.482732

Schroeder, R. (2010). Being there together. New York, NY: Oxford University Press. doi:10.1093/acprof:oso/9780195371284.001.0001

Skinner, B. F. (1965). The technology of teaching. Proceedings of the Royal Society of London, 162(989), 427-443. doi:10.1098/rspb.1965.0048

Slater, M. (1999). Measuring presence. Presence: Teleoperators and Virtual Environments, 8(5), 560565. doi:10.1162/105474699566477

Slater, M., \& Steed, A. J. (2000). A virtual presence counter. Presence: Teleoperators and Virtual Environments, 9(5), 413-434.

Stahl, G., Koschmann, T., \& Suthers, D. D. (2006). Computer-supported collaborative learning. In K. Sawyer (Ed.), The Cambridge handbook of the Learning Sciences (pp. 409-426). New York, NY: Cambridge University Press.

Steuer, J. (1993). Defining virtual reality. Journal of Communication, 42(4), 73-93. doi:10.1111/j.14602466.1992.tb00812.x

Suppes, P. (1974). The place of theory in educational research. Educational Researcher, 3(6), 3-10. doi:10.3102/0013189X003006003

Vergara, V., Caudell, T., Goldsmith, P., \& Alverson, D. (2008). Knowledge-driven design of virtual patient simulations. Innovate, 5(2).

Vygotsky, L. S. (1978). Mind in society. Cambridge, MA: Harvard University Press.

Wang, F., \& Burton, J. K. (2013). Second Life in education: A review of publications from its launch to 2011. British Journal of Educational Technology, 44(3), 357-371. doi:10.1111/j.14678535.2012.01334.x

Warburton, S. (2009). Second Life in higher education. British Journal of Educational Technology, 40(3), 414-426. doi:10.1111/j.1467-8535.2009.00952.x

Wehner, A. K., Gump, A. W., \& Downey, S. (2011). The effects of Second Life on the motivation of undergraduate students learning a foreign language. Computer Assisted Language Learning, 24(3), 277-289. doi:10.1080/09588221.2010.551757

Wenger, E. (1998). Communities of practice. New York, NY: Cambridge University Press. doi:10.1017/CBO9780511803932

Whitton, N. (2012). The place of game-based learning in an age of austerity. Electronic Journal of eLearning, 10(2), 249-256.

Wilson, A. B., Brown, S., Wood, Z. B., \& Farkas, K. J. (2013). Teaching direct practice skills using webbased simulations. Journal of Teaching in Social Work, 33(4-5), 421-437. doi:10.1080/08841233.2013.833578

Winn, W. (1993). A conceptual basis for educational applications of virtual reality (No. R-93-9). Washington, DC: Human Interface Technology Laboratory. Retrieved from http://www.hitl.washington.edu/projects/education/winn/winn-paper.html

Witmer, B. G., \& Singer, M. J. (1998). Measuring presence in virtual environments. Presence: Teleoperators and Virtual Environments, 7(3), 225-240. doi:10.1162/105474698565686

Wu, W. H., Hsiao, H. C., Wu, P. L., Lin, C. H., \& Huang, S. H. (2012) Investigating the learning-theory foundations of game-based learning. Journal of Computer Assisted Learning, 28(3), 265-279. doi:10.1111/j.1365-2729.2011.00437.x

Corresponding author: Swee-Kin Loke, swee.kin.loke@otago.ac.nz

Australasian Journal of Educational Technology (C) 2015.

Please cite as: Loke, S-K. (2015). How do virtual world experiences bring about learning? A critical review of theories. Australasian Journal of Educational Technology, 31(1), 112-122. 